\title{
TRABAJO SOCIAL EN EL CAMPO DE ACTUACIÓN DE INMIGRACIÓN Y REFUGIO
}

\section{CARMEN SANTOS AGUADO}

Profesora Titular de la E.U.T.S.

Universidad Complutense de Madrid

\section{INTRODUCCIÓN}

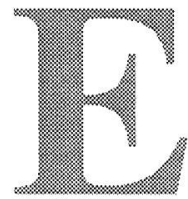

1 campo de actuación con inmigrantes y refugiados ha sido desarrollado en España durante las últimas décadas.

Poco y escaso hay publicado sobre este área de intervención. En concreto, cabe resaltar que, hasta el momento actual, los trabajadores sociales vinculados a la misma han sido pioneros en la atención en España a estos colectivos. Inician su labor desde instituciones y servicios que son creados específicamente para ello (los primeros programas oficiales se iniciaron en la década de los años 70), carecen de preparación específica y aprenden a actuar de su propia experiencia.

Los trabajadores sociales que hemos realizado este trabajo somos conscientes de la importancia y necesidad de una preparación adecuada para intervenir en este campo de actuación, que consideramos diferente y peculiar por la problemática que conlleva.

Nuestro objetivo a la hora de realizarlo es exponer los aspectos fundamentales que caracterizan y delimitan la actuación profesional, se trata por lo tanto de plantear:

$1^{\circ}$ Que el fenómeno de la inmigración y refugio conlleva una problemática específica.

$2^{\circ}$ Que el trabajador social debe conocerla y sensibilizarse ante ella.

$3^{\circ}$ Que su actuación debe ir orientada por una metodología que parte de la investigación constante de las «necesidades sentidas» en cada momento, así como del proceso de inserción que todo inmigrante o refugiado va a iniciar desde su llegada a España.

$4^{\circ}$ Que, finalmente, como función propia, el trabajador social debe responder a estas necesidades con recursos adecuados, previendo y solucionando posibles problemas desencadenantes de otras más graves situaciones.

Entendemos, por lo tanto, que es necesario, a la hora de trabajar en el campo de actuación con inmigrantes y refugiados, tanto una prepa- 
ración inicial al mismo, como una supervisión y evaluación constante del trabajo realizado, que mejore y actualice nuestra labor.

Por otra parte, queremos señalar que, al mismo tiempo, existen aspectos comunes con cualquier área de intervención en trabajo social. En este campo, el profesional sigue una línea de actuación fundamentada en una filosofia humanista, apoyada en los Derechos Humanos, así como en los principios y valores tradicionales del trabajo social, basada: en la aceptación del cliente, la valoración de la situación del mismo, la diagnosis, el contrato, la relación de ayuda, la evaluación del progreso de la relación y el final de la misma'.

De igual forma, este proceso de intervención sigue el modelo científico intrínseco al trabajo social: estudio, valoración, planificación, ejecución y evaluación ${ }^{2}$.

Como veremos y desarrollaremos, la especialidad en este área de intervención radica en la aplicación de todo ello desde el proceso que conlleva la inmigración y el refugio; proceso que hemos diferenciado en tres fases:

1. Fase de acogida. La llegada.

2. Fase tutelada. La adaptación. El asentamiento.

3. Fase autónoma. La inserción. La integración.

Asimismo, en el presente trabajo haremos referencia a las técnicas que deben utilizarse para poder alcanzar los objetivos de cada fase.

\section{TERMINOLOGÍA. DEFINICIONES}

Para todo aquél que no ha intervenido en este campo de actuación, cabe precisar que existe una diferencia terminológica que indica situaciones diferentes y problemáticas distintas, aunque igualadas todas ellas por la experiencia de inmigración, es decir, por la experiencia de colectivos e individuos que por diferentes motivos se ven obligados a abandonar sus tierras de origen y asentarse por tiempo indefinido en otros países.

Así, nos vamos a encontrar con personas que, teniendo como denominador común la situación de inmigración, son llamadas con distintas «voces»:

1. Refugiados o Asilados «son personas que tienen fundados temores de ser perseguidas en su país de origen por motivos de raza, religión, nacionalidad, pertenencia a un determinado grupo social u opiniones politicas; se encuentran fuera de su país, de su nacionali- 
dad y no pueden o, a causa de dichos temores, no quieren acogerse a la protección de tal país, o que careciendo de nacionalidad y hallándose, a consecuencia de tales acontecimientos, fuera del país donde antes tuvieran su residencia habitual, no pueden, o a causa de dichos temores, no quieren regresar a él ${ }^{3}$. Proceden normalmente de países donde existen dictaduras o regímenes autoritarios.

2. Desplazados. Se trata de una nueva figura que se introduce en la legislación española en 1994 con la modificación de la ley de asilo, con la finalidad de dar protección a aquellas personas que «a consecuencia de conflictos o disturbios graves de carácter político, étnico o religioso se hayan visto obligadas a abandonar su país de origen o no puedan permancer en el mismo».

3. Inmigrantes en situación regular. Son personas de nacionalidad extranjera que desean o se ven obligadas a emigrar de su país de origen por motivos generalmente de tipo económico. La mayor parte procede de países del tercer mundo.

4. Extranjeros en situación irregular. Son personas de nacionalidad extranjera que se encuentran fuera de sus países de origen y no tienen ningún estatuto legal que les permita permanecer o residir en el país donde se encuentran. En esta situación podrían quedar los solicitantes de asilo a quienes no se les reconozca el estatuto de refugiado.

\section{PROBLEMAS PSICOSOCIALES DERIVADOS DE LA INMI- GRACIÓN}

\subsection{Marco teórico}

El hecho social de la migración, señala J. Castillo Castillo 4 , «no se produce al azar, sino que acaece dentro del entramado conformador de una específica estructura social o, dicho con otras palabras, es un proceso selectivo por el que diferentes grupos y categorías de personas se trasladan de un lugar a otro»».

Tampoco es un hecho nuevo de este siglo, ni de estos últimos años; la historia nos señala como desde siempre han existido migraciones, que se han convertido en masivas en determinados momentos, y que han hecho cambiar el panorama mundial, originando desde una mirada retrospectiva «ricos mestizajes culturales».

. Equipo de trabajo de Cruz Roja Española. Una experiencia de trabajo social con refugiados en Cuadernos INAS, núm. 2, «Los refugiados en España», pág.21. INAS, 1983.

4 Castillo Castillo, J. Teorías sociológicas de las migraciones humanas. Diversidad e integración en «XII Congreso Mundial de Sociología», pág. 2. Madrid 1990. 
Así y todo, desde el punto de vista sociológico, es un fenómeno poco teorizado; además, la mayor parte de las teorías existentes centran su atención en aspectos concretos de este hecho: aspectos mentales, económicos, sociales, que en ningún momento dan la dimensión global que el tema requiere. De este modo, las «teorías de la asimilación», como las del «conflicto social» y la «teoría marxista» limitan, por así decirlo, la extensión de este problema.

En el artículo señalado del profesor J. Castillo Castillo se plantea una teoría más rica que estas otras, la denominada «teoría de la naturaleza global de las migraciones» ${ }^{5}$, desarrollada por A. Portes y R.L. Bach, que tratan de encontrar un modo de abordar el proceso migratorio en su totalidad a partir de cuatro aspectos específicos, son los que de forma aislada desarrollan las teorías mencionadas anteriormente. Así, hablan de:

1. Las causas migratorias. La explicación más común está contenida en las llamadas teorías de los factores de expulsión y de atracción. Ciertos factores económicos, sociales y políticos adversos empujan a abandonar el lugar de origen mientras que otros factores de naturaleza similar favorables mueven a desplazarse a otro lugar; son las llamadas «push-pull theories».

2. La estabilidad de migraciones. Es otra de las facetas típicas de las migraciones, referida a su diverso grado de estabilidad: hay corrientes migratorias de corta duración o que se prolongan con el tiempo, acabando por resultar definitivas. Se hablaría de progresivas integraciones o, por el contrario, de retornos.

3. El cometido de las migraciones. Abordan el papel que las migraciones cumplen con respecto al país receptor. Se señalan tres tipos de teorías en este caso:

a) Aquéllos que conciben el fenomeno migratorio como una aportación suplementaria de mano de obra de un mercado de trabajo escaso en el país anfitrión.

b) Aquéllos que, partiendo del conflicto social, sostienen que la importación en masa de trabajadores extranjeros no le procuran a éste mayor beneficio, sino que favorecen bien a la población nativa en su conjunto, bien a la clase empresarial que los utiliza para debilitar la fuerza de la clase obrera nativa. La principal consecuencia de la inmigración es la división de la clase trabajadora en dos estratos contrapuestos: el formado por los nativos y el formado por los inmigrantes. La inmigración en masa no favorece así ni a unos ni a otros. 
c) El tercer grupo de teorías parte de una visión conflictiva de la sociedad. Comienzan sosteniendo, como el anterior, que los inmigrantes no se distribuyen homogéneamente en la estructura laboral del país receptor: el tipo de trabajo del que se hacen cargo es el que rechazan los nativos. Por eso, a diferencia de la interpretación anterior, estas teorías defienden la existencia de un mercado de trabajo dual, llamado así por la división del mercado en dos sectores: uno de ellos oligopactista, con seguridad en el empleo, y otro competitivo dominado por la inseguridad laboral. Los trabajos inseguros -rechazados por los trabajadores nativos cualificados- se dejan para las mujeres, los viejos, los jóvenes y los inmigrantes. Se usa así una clase marginal, heterogénea en su composición, que se distingue claramente de la clase trabajadora del sector privilegiado.

4. La adaptación de los emigrantes. Por último, los estudios de las inmigraciones, continúa señalando el profesor J. Castillo Castillo, han preguntado por el resultado final de la permanencia en el país receptor de la población inmigrante. Un grupo de teorías de la asimilación entiende que se da la integración definitiva; otro grupo de teorías, el de las conflictivistas, entiende que no se llega a dar nunca.

El objeto de la teoría de la asimilación consiste en determinar el diverso grado de integración de la colectividad inmigrante en la sociedad receptora. El modelo al que acuden Portes y Bach es el descrito por M. Gordon. Según este autor, el proceso de asimilación comienza con la aculturación de los inmigrantes, o absorción por éstos de los valores y normas propios de la población nativa; le sigue la asimilación estructural o amplia participación de la población inmigrada en los grupos primarios de la sociedad anfitriona; a continuación, la amalgamación, o celebración de matrimonios mixtos entre inmigrantes y nativos, para terminar con el desarrollo de una identidad nacional común. A juicio de Gordon, una vez que se ha producido la aculturización, el proceso de asimilación no tiene por qué atenerse a una renuncia lineal, pudiendo esto desembocar bien en una aceptación por los inmigrantes de los valores y normas dominantes (solución «Angloconformity»), bien en una mezcla de culturas respectivas (solución «melting pot»), bien en una convivencia de las mismas (solución cultural pluralista). Mas, sea cual sea el resultado del proceso de asimilación, lo cierto es que el principal hallazgo de estas teorías es el de que el contacto entre una nueva minoría extranjera y una mayoría establecida conducirá, a través de una serie de etapas, a una eventual mezcla de valores, símbolos e identidades. Se considera que esta integración en una sola sociedad y cultura, o quizás en varios grandes subsegmentos, «es una cosa buena». 
Por el contrario, las teorías que parten de la inevitable presencia del conflicto social no creen en este proceso secuencial de asimilación del inmigrante: no comparten la creencia de que la sucesión de generaciones cause de modo obligado el olvido de la cultura primera. Pues es un hecho comprobado que, en ocasiones, se produce un resurgimiento del originario espíritu nacional, así como un rechazo de la cultura dominante.

A continuación, vamos a señalar lo que de alguna manera hemos constatado en nuestro trabajo en este área, es decir, que estos procesos de asimilación o rechazo comportan una serie de vivencias que hemos denominado como «problemas psicosociales».

\subsection{Problemas psicosociales derivados de la inmigración}

Vamos a señalar tres aspectos, considerados como «ejes», que agrupan la problemática de los grupos definidos en un principio: refugiados e inmigrantes.

a) La decisión de abandonar el país de nacimiento comporta una serie de condiciones objetivas y subjetivas; estas últimas juegan un papel fundamental para la toma de la decisión. Bien es sabido que condiciones que para nosotros son intolerables: persecución, amenaza, falta de posibilidades educativas, trabajo, falta de asistencia sanitaria etc., para otros pueden resultar soportables ${ }^{6}$. Distintas teorías se refieren en este caso a este aspecto; por señalar una, el matrimonio Grinberg? ${ }^{7}$, señala la existencia de dos tipos de individuos: los que necesitan estar siempre en contacto con gentes y lugares conocidos (ocnofílicos) y los que disfrutan cuando tienen la posibilidad de ir a lugares desconocidos e inician nuevas relaciones (filobáticos). De cualquier forma, esta decisión es fundamental y definitiva a la hora de soportar las dificultades en el país receptor.

b) La mayor parte de los inmigrantes o refugiados abandonan su país bien con la intención de regresar, bien con la intención de comenzar una nueva vida en otro país, desvinculándose completamente de la familia, etc. En todos los casos, este abandono del ambiente habitual familiar y social, y la llegada a un sitio desconocido «fantaseado» o idealizado, puede acarrear un intenso sufrimiento físico y cultural. A menudo, el sentimiento común es encontarse con un futuro no esperado.

6 El trabajo con refugiados y solicitantes de asilo, Cruz Roja Española-Ministerio de Asuntos Sociales. INSERSO. Madrid, 1994.

7 Grinberg, León y Grinberg, Rebeca. Psicoanálisis de la emigración y el exilio. Alianza Editorial. Madrid. 
Al desplazarse «pierden» gran parte de sí mismos: modo y medio de vida, identidad, apoyo afectivo y marco de conocimiento social; aflorando sentimientos inesperados.

La llegada al país de acogida produce un choque cultural que genera reacciones psicológicas que se manifiestan como duelos postergados, que pueden llevar paulatinamente a la sensación de desamparo y que sólo es compensado bien por la esperanza del retorno, bien por el aislamiento entre sus propios compatriotas.

c) La sociedad de acogida juega un papel definitivo en facilitar medios y recursos para la adaptación de estos colectivos. La sensibilización de la misma favorece toda una serie de cuestiones en relación a esta adaptación, al igual que el respeto por las consideraciones interculturales y las aspiraciones de la población emigrante o refugiada.

Como consecuencia de estos aspectos, los problemas que viven estos colectivos se encuentran dentro de las siguientes esferas que posteriormente trataremos en el apartado de Metodología:

1. Identidad y lengua.

2. Etnicidad e identidad étnica.

3. Pérdida de la raíz cultural.

4. Experiencia de aculturación y adaptación transcultural.

5. Mecanismos de protección, bloqueo, rechazo.

6. Racismo y xenofobia. Discriminación. Relaciones entre la mayorías y las minorías ${ }^{8}$.

\section{EVOLUCIÓN HISTÓRICA DE LA INTERVENCIÓN EN ESPA- ÑA CON ESTE COLECTIVO: INSTITUCIONES, OCUPADAS EN EL TEMA. LA LEGISLACIÓN ANTERIOR Y VIGENTE}

Como se ha repetido en numerosas ocasiones, España ha pasado de ser un país de emigración a convertirse en un país de inmigración. Este cambio, ocurrido en la última década, conlleva una preocupación paulatina por parte del Gobierno en relación al desarrollo de programas y servicios que estos colectivos demandan. A su vez, España se ha enfrentado a este reto importante: la promulgación de las leyes necesarias para regular estos fenómenos al igual que lo hicieran otros países europeos que tradicionalmente han sido receptores de inmigrantes y refugiados.

El cambio ocurrido así en nuestro país ha sido tanto cualitativa como cuantitativamente considerable. El aumento de departamentos y 
servicios dentro de instituciones, la creación y desarrollo asociaciones y organizaciones no gubernamentales -ONG's- para la atención a estos colectivos, la dotación presupuestaria para el mantenimiento de las mismas y los recursos que ofrecen a esta población han ido poco a poco configurándose y obteniendo el reconocimiento tanto de los responsables de la Administración como del colectivo profesional que ha ayudado a ello.

A continuación, vamos a fijarnos en los aspectos señalados: la configuración de un plantel de instituciones y ONG's encargadas del tema $y$, por otra parte, la igualmente lenta conformación del aparato legislativo necesario.

La promulgación de la Ley de Extranjería, así como la de la Ley de Asilo y Refugio, muestran un cambio de actitud y un interés por parte del Gobierno para regular la situación de estos colectivos en España. Por otro lado, esta promulgación nos permite trazar una especie de línea divisoria. Así, vamos a poder hablar de un antes y un después de la promulgación de estas leyes y de sus sucesivas modificaciones. Unido a ello, se experimenta un cambio paulatino en la responsabilidad, competencias y profesionalización de las agencias encargadas del tema. Además, tenemos que señalar en este momento que todo ello ha sido debido a la participación conjunta de los profesionales que han intervenido desde sus marcos de actuación, haciendo posible la revisión constante de programas, leyes y actuaciones hacia estos colectivos.

\section{I. Evolución de las instituciones}

España, en la década de los cuarenta y como consecuencia de la Guerra Civil, era más conocida en el mundo como nación generadora de refugiados que como país de acogida. Las primeras estadísticas relacionadas con la acogida de refugiados datan de finales de 1959. En ellas se señalan unos 1.320 refugiados, en su mayoría procedentes de países centroeuropeos, cuyo éxodo estuvo motivado por las grandes contiendas mundiales, y que fueron acogidos en nuestro país.

A partir de esta fecha, empezaron a llegar ciudadanos cubanos que huían del régimen político implantado en su país. Los primeros programas de ayuda datan de 1961 y son organizados por diversas agencias voluntarias en colaboración con el ACNUR. Se crean pensiones vitalicias para personas mayores, comedores colectivos, roperos y un servicio de recepción en el aeropuerto de Barajas. También se facilitan servicios para la emigración de cubanos hacia EEUU.

En 1965 se realiza un estudio sociológico de esta población y su situación real, programándose una serie de ayudas de emergencia, asistencia sanitaria, asentamientos, becas, etc. 
A partir de 1973, comienzan a llegar ciudadanos latinoamericanos, procedentes del cono sur -se cree que fueron unos 50.000 entre refugiados y emigrantes-. La problemática que plantean esos colectivos crea la necesidad de establecer servicios sociales especializados.

En 1974, el Gobierno español encomienda a la Cruz Roja la realización de programas de asistencia a refugiados en todo el territorio nacional en colaboración con ACNUR. En octubre de 1979, se crea en la Asamblea de la Cruz Roja Española el «Departamento de refugiados» con personal delegado en todas las asambleas provinciales, para poder atender de este modo a los solicitantes de asilo y refugio en todo el territorio nacional.

En este mismo año, 1979, se crea la Comisión Española de Ayuda al Refugiado-CEAR-, dedicada a promover la solidaridad de la sociedad española a favor de los refugiados, sin discriminaciones por motivos de raza, ideas, creencias, religiones $u$ origen nacional.

Durante los 10 años siguientes, son estas dos agencias, junto con la Delegación diocesana de extranjeros e inmigrantes (denominada hoy ASTI), dedicada a la ayuda de los colectivos de inmigrantes, el Comité Internacional de Rescate (reasentamientos) y la Comisión Católica de Migraciones, las principales organizaciones que dispensan sus servicios a esta población.

Hasta el año 1984, el Ministerio de Trabajo y Seguridad Social, a través de la Dirección General de Acción Social, era quien se encargaba de la distribución de fondos para todas las agencias con programas de asistencia a extranjeros y refugiados.

En 1990, el INSERSO, dependiente del Ministerio de Asuntos Sociales $^{9}$, tiene encomendada la gestión y desarrollo de una red de centros de acogida a refugiados y programas de integración social en favor del colectivo de refugiados y asilados. Se trataba de un plan global, de carácter estatal, cuya gestión se realizaba en coordinación con los ministerios comprometidos en esta materia (Ministerio del Interior, Asuntos Exteriores, Trabajo y Seguridad Social y Justicia).

El programa del INSERSO se articulaba básicamente a través de tres grandes ejes de actuación: programa de acogida a solicitantes de asilo y refugio, programa de protección social a refugiados y asilados y acciones de carácter global. Para el primer programa, se consolidaron los CAR (Centros de atención a refugiados), regulados por orden ministerial 13/1/1989, puestos en funcionamiento desde 1987. Para el resto, se pusieron en funcionamiento diferentes programas de formación, ayudas de guarderías, etc.

Amancio Roberto (sic) Centros y programas del INSERSO en revista Minusval, núm. 87, dossier «Los refugiados en la Europa comunitaria y España», pp. 35-36. Ministerio de Asuntos Sociales: INSERSO. Madrid, 1993. 
En 1992 se inagura la Oficina de Asilo y Refugio-OAR-10, con dos objetivos claros:

a) crear una oficina dedicada exclusivamente a los aspectos relativos al colectivo de refugiados: mejorar en la tramitación, instrucción y estudio de las solicitudes de asilo. Garantizar la necesaria celeridad en el examen individualizado de las solicitudes de asilo.

b) evitar la posible utilización fraudulenta de la vía de asilo/refugio por parte de los inmigrantes económicos, para sustraerse a la aplicación de la normativa general en materia de extranjería.

La OAR, fundamentalmente, dependía ${ }^{10}$ de la Secretaría General de la Dirección General de Política Interior; orgánicamente, su personal estaba ascrito en parte a la Comisaria General de Documentación, en parte al Ministerio de Asuntos Sociales, y en parte a la Dirección General de Política Interior. Sus prestaciones son tanto la tramitación y estudio de las solicitudes de asilo como el hacer de filtro para derivar a los solicitantes y refugiados hacia los centros de acogida y programas del INSERSO, Cruz Roja y otras ONG's con asistencia a refugiados.

En relación con el colectivo de inmigrantes, cuya estancia en nuestro país es debida a motivos económicos, igualmente se han incrementado las respuestas por parte tanto de ONG's, de la Administración, como de asociaciones que han ido creado los propios inmigrantes, (entre otras, AMOE, AEME, ATIME, FEDORA -refugiados e inmigrantes-, etc.).

De esta forma, nos encontramos en esta década señalada con la participación de la Cruz Roja, CEAR, Cáritas, ASTI, KARIBU, Médicos del Mundo, Comisión Catolica de Migraciones, Comité Internacional de Rescate, IEPALA, sindicatos (UGT, CCOO, USO) y un constante número de agencias que se crean para prestar sus servicios y facilitar el proceso de incorporación de este colectivo, como es el caso de la recien configurada «Madrid Puerta Abierta».

Por otra parte, también han existido cambios cualitativos importantes sobre materia de inmigración, el primero, referido al hecho de haber asumido el Ministerio de Asuntos Sociales, a través de la Dirección General de Migraciones, las competencias sobre este tema; en segundo lugar, a través de la participación de todas las Administraciones Publicas, tanto a nivel de la Administración del Estado, como de las Administraciones Autonómicas y Municipales con la aprobación, en diciembre de 1994, por el Consejo de Ministros, del Plan para la Integración Social de los Inmigrantes ${ }^{11}$, presentado por el Ministerio

1 Plan para la integración social de los inmigrantes. Ministerio de Asuntos Sociales. Dirección General de Migraciones. Madrid, 1995. 
de Asuntos Sociales, compuesto por una serie de medidas que eviten actuaciones contrapuestas en estas materias por parte de los responsables en la atención a estos colectivos, respetando las competencias de cada uno. Así, se establecen medidas de caracter normativo, de tipo socio-laborales, educativas, culturales y, finalmente, para la participación social, pretendiendo con ello la regulación de las condiciones legales de permanencia y estancia en territorio español. En el primer caso, la orientación, y formación profesional en el segundo caso; el intercambio y el conocimiento mutuo de las culturas, la información al sistema educativo y programa de información en el tercer caso..., y, finalmente, a través de la participación social, la animación hacia la formación de asociaciones y organizaciones participativas de inmigrantes. Iniciativas que, como se señalan en el Plan, nacen en el sector público, pero para ser verdaderamente efectivas requieren encontrar eco en el conjunto de los ciudadanos.

Finalmente, el tercero de los cambios acaecidos en estos últimos años es la constitución en Madrid del Foro de los Inmigrantes, como organismo que tiene la finalidad de promover la participación e integración social de los trabajadores extranjeros legalmente establecidos en la sociedad española, y servir de vehículo para debatir los asuntos más importantes relacionados con los inmigrantes. El foro está compuesto por un presidente y treinta vocales, que tendrán voz y voto en esta nueva plataforma. Por parte de la Administración Pública están los Ministerios de Asuntos Sociales, Educación y Ciencia y Cultura, junto con la Comunidad de Madrid, la Generalitat de Cataluña y Junta de Andalucía (total 10 vocales). Las Organizaciones Sociales presen$\tan 20$ vocales, entre los que hay nueve ONG's y ocho asociaciones. Además, hay que añadir la Cruz Roja Española (1 voto). La constitución del Foro supone el compromiso conjunto de todas las partes implicadas, uniendo sus fuerzas en pos de un objetivo común: tratar el problema de la inmigración en España con la responsabilidad y operatividad que merece.

\subsection{Legislación anterior y vigente}

Este apartado puede vincularse al anterior, por el cambio que ha supuesto la atención a estos colectivos desde la entrada en vigor de una legislación que regulara las estancias y concediera estatutos a los mismos.

Como señala M.P. Corredera ${ }^{12}$, España ha tenido la necesidad de adecuar su legislación al marco jurídico internacional y, más reciente-

12 Corredera García, M. P.; Díez Cano, L. Santiago. La política de extranjería en España, pág. I2 I. 
mente, al europeo, siendo por ello necesaria y urgente la promulgación de una ley básica que regulara el régimen de los extranjeros afincados en el país. Como define esta autora, «prolija y dispersa» era la normativa que regulaba el status y tratamiento de los extrajeros inmigrados, antes de aprobarse la ley orgánica $7 / 1985$ de 1 de julio sobre derechos y libertades de los extranjeros en España (BOE 158 de julio 1985), cuyo Real Decreto, por el que se regulaba el Reglamento de aplicación de dicha Ley, ha sido modificado en la actualidad por el R.D. 155/1996 publicado en el B.O.E. de 23 de febrero de 1996.

Hasta la aprobación de la ley orgánica señalada, nuestro ordenamiento jurídico había carecido, desde el Real Decreto 17-11-1852, de una normativa que, con pretensión de generalidad, recogiera, formulara y sintetizara los principios que debían informar la situación de extranjería en sí misma, y en los aspectos más importantes, evitando la proliferación de disposiciones de distinto rango, que habían venido regulando esta materia, convirtiendo en caótica la legislación sobre extranjeros, dificultando su conocimiento a los afectados, aumentando su indefensión y facilitando ciertas arbitrariedades administrativas de dudosa legalidad.

Desde el punto de vista internacional, España había ratificado varios Convenios Internacionales: como la Declaración de los Derechos Humanos, el Pacto Internacional de Derecho, Civiles y Políticos de 1966, el Convenio Europeo para la Protección de los Derechos Humanos y Libertades Fundamentales (Roma 1950), y la adhesión el 14/8/ 78 a la Convención sobre el Estatuto de los Refugiados, suscrita en Ginebra el 22/7/1951 y su Protocolo adicional suscrito en Nueva York en 1967. Tras estas adhesiones, España entra a formar parte de los Estados democráticos de la comunidad internacional que constituyen una tierra de asilo. Así, en relación con estos compromisos, y en base al artículo 13.4 de la Constitución española, se aprueba la ley 5/1984 de 26 de marzo reguladora del derecho de asilo y la condición de refugiado. Poco después, esa ley, que reviste rango ordinario, fue desarrollada por el Real Decreto 511/1985 que aprueba el Reglamento para la aplicación de la ley reguladora del Derecho de asilo y de la condición de refugiado.

De esta forma, nos encontramos con una legislación «joven» en este terreno, de sólo once años de aplicación.

El resultado puede valorarse como positivo desde el punto de vista de la formulación teórica que ambas leyes, de Extranjería y de Asilo, recogen. Ahora bien, al analizar el conjunto de medidas que permiten regular estas disposiciones, es cierto que han suscitado claras polémicas y críticas. Así, en diciembre de 1990, el Gobierno español presentó al Congreso de los Diputados un informe señalando los principales problemas planteados al desarrollar la ley, relativos a la situación de 
los extrajeros en España y a las líneas básicas de la política española de extranjería. La pretensión global, continúa señalando M.P. Corredera, es la de controlar el flujo masivo de inmigrantes, salvando el tiempo, el orden y la cohesión social, así como las posibilidades de integración de los inmigrantes ilegales. Todo ello dentro de las líneas esenciales que marca el resto de los países de la Comunidad Europea, que tienden a dominar el volumen de inmigrantes y canalizar los flujos. Estas medidas políticas, bajo la forma de proposición no de ley, fueron presentadas en el Pleno del Congreso el 13 de marzo de 1991, aprobándose íntegramente el 9 de abril de 1991.

No obstante, al objeto de subsanar las deficiencias encontradas en la aplicación de la Ley de Asilo 5/84 y de cara a la progresiva armonización de las políticas de asilo en los países de la Unión Europea se revisa la antigua ley, que es modificada por la ley 9/1994 de 19 de mayo 1994. Dicha modificación obedece a dos fines claros:

1. Garantizar la necesaria celeridad en el examen de las solicitudes de asilo.

2. Impedir la utilización fraudulenta del sistema de protección a los refugiados con fines de inmigración económica.

Posteriormente, se elabora y emite el Real Decreto 203/1995 (10/2/ 1995), por el que se aprueba el Reglamento de aplicación de la ley 5/ 1984 de 26 de marzo, reguladora del derecho de asilo y de la condición de refugiado, modificada por la ley 9/1994 de 19 de mayo.

La conclusión a estos aspectos es recogida también en el artículo señalado de M.P. Corredera ${ }^{13}$, quien expone la existencia de dos tendencias contradictorias en España sobre este tema. Por una parte, la voluntad del Gobierno de reconocer los derechos de los inmigrantes, tratando de equiparar su situación a la de los nacionales. Por otra parte, de forma paralela, existe la voluntad de no desvincularse de los tratados internacionales, concretamente de las orientaciones comunitarias (Acuerdo Schengen, Trevi, Maastrich y grupos ad hoc), haciendo prevalecer los intereses del mercado laboral español.

De una manera o de otra, lo que con esto queríamos resaltar, es que toda la atención social prestada a este colectivo se enmarca dentro de los límites que establece la legislación vigente. Las ayudas y programas establecidos para este colectivo siguen la doble vertiente señalada: por una parte existen los programas específicos para Refugiados y, por otra, los dirigidos a Inmigrantes. La práctica del trabajo diario plantea, como es común en nuestra profesión, dificultades constantes desde el momento de conseguir lo previsto en dichos programas. En este campo de actuación, nos encontramos siempre con la necesidad de 
adaptar estos programas a las peculiaridades de cada persona; el tiempo ${ }^{14}$ de vivencia de cada uno es, a su vez, diferente. La flexibilidad de planteamientos, se convierte en la rutina constante de esta intervención. Somos los profesionales, cuya tarea es acercar los recursos a los beneficiarios, quienes constatamos estas diferencias.

La metodología de la intervención del trabajador social que exponemos a continuación -en el artículo de M. ${ }^{a}$ Socorro Escobar Rubio y Nieves Gascón Navarro, "Metodología del trabajo social con inmigrantes y refugiados»- debe entenderse desde los aspectos que hemos indicado. Esperamos quede demostrado de forma sobrada que la complejidad del tema requiere una reflexión y evaluación constante de las actuaciones diarias.

14 Santos Aguado, Carmen. El camino del exilio. Revista de Cruz Roja Española (diciembre, 1983). 